Tarifa S. Almulhim ${ }^{1}$

Article info:

Received 02.12.2019

Accepted 13.04.2020

UDC -519.816

DOI - 10.24874/IJQR14.04-07

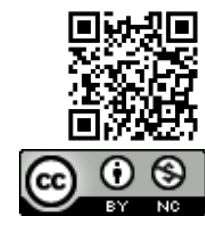

\section{MULTI-CRITERIA EVALUATION OF INSURANCE INDUSTRIES PERFORMANCE: AN ANALYSIS OF EDAS BASED ON THE ENTROPY WEIGHT}

Abstract: Insurance industries have grown remarkably since the late 1990s. Governments require a benchmarking tool to measure their insurance industry's performance according to specific various indicators. The best practice benchmarking of insurance can be achieved by evaluating numerous insurance industries through prioritizing and identifying the top industries. This paper presents a multi-criteria evaluation framework for insurance performance of Organization for Economic Cooperation and Development (OECD) countries by investigating conflicting and incommensurate insurance indicators for the period of 2010-2017. For the basis of the evaluation, eight main insurance performance inductors were identified and then their weights were determined using the entropy method. The resultant entropy weights were then applied in the evaluation based on distance from average solution (EDAS) method for determining preferential rankings of insurance industries. The ranked insurance industries were classified into groups of similar levels of performance. Sensitivity analysis was applied to the main criteria to examine the robustness of the prioritizing results. The results indicate insurance markets in United States, the United Kingdom, Germany, France, and Japan are ranked higher than the remaining 25 OECD countries.

Key words: Multi-Criteria Decision-Making; EDAS; Shannon's entropy; insurance industries; OECD countries

\section{Introduction}

The development of the insurance industry development is a strong promoter of economic growth sustainability for countries worldwide. The insurance industry has witnessed an important and enhanced growth since the late 1990s (Arena, 2008). Since 1950 , a prominent portion of the global insurance industry has grown at an annual rate of over 10\% (Chen et al., 2012). Many studies focused on understanding insurance market growth with economic and financial sectors in industrialized and developed countries. In this regard, various studies have been conducted in insurance industry, including but not limited to Ward and Zurbruegg (2000), Arena (2008), Haiss and Sumegi (2008), Lee (2011), Chen et al. (2012), Pradhan et al. (2015), and Pradhan et al. (2017). Authors considered several variables and indicators of performance such as: gross claims payments, insurance density, and insurance penetration (Pradhan, Arvin \& Norman, 2015; Pradhan et al., 2017). Recent theoretical and empirical approaches to insurance performed at the

${ }^{1}$ Corresponding author: Tarifa S. Almulhim

Email: talmulhim@kfu.edu.sa 
international level are still concentrated in two main approaches, causality approaches and data envelopment analysis (DEA), and their extended approaches (Pradhan, Arvin \& Norman, 2015; Pradhan et al., 2017).

Despite the increasing research on insurance markets in developed and emerging countries, several issues remain unclear: how the insurance performance indicators (IPIs) in various countries, which are conflicting and incommensurate in its nature, can be weighed and prioritized, and determining how to select the country most suitable for benchmarking considering each conflicting and incommensurate IPIs. In this context, what is the ranking of insurance industries across multiple countries based on IPIs? Which countries are at a similar level of efficient insurance performance according to IPIs? To the best of my knowledge, no researchers have focused much on the insurance performance in the Organization for Economic Cooperation and Development (OECD) countries by considering the issues mentioned above. OECD insurance industries are worthy of study since annual real premium growth in the life and/or the non-life insurance sectors in the OECD countries continued to rise in 2017 according to Global Insurance Market Trends (OECD, 2018). OECD is an international economic organization that was officially established in 1961 and now has 36 member countries worldwide, from North and South America to Europe and Asia Pacific. Its mission is providing a forum to promote governments to work together for comparing policies, experiences, solutions to common global issues, and recognizing good practices.

In accordance with the issues emphasized above, the current research problem in insurance is a conflicting and incommensurate Multi-Criteria problem (the IPI) with a finite number of feasible alternatives (the OECD countries). This problem is called a discrete Multi-Criteria decision-making (MCDM) problem (Triantaphyllou, 2000). Multi-Criteria analyses offer flexible techniques to handle the complexity of the current research issues. In the literature, many different MCDM methodological approaches were used to calculate weighting multiple criteria and prioritize alternatives (Ture et al., 2019; Ponsiglione et al., 2018). In typical MCDM methods, the weights of criteria reflect the relative importance in decision process. Many objective weighting procedures were developed in the literature for identifying criteria weights, such as Shannon entropy, multiple objective programming, etc. (Wang \& Lee, 2009). Shannon entropy is a suitable method for assessing the relative importance of criteria (Wang \& Lee, 2009; Gray, 2011; Danesh et al., 2018).

Outranking methods in Multi-Criteria analyses, which focus on finding a feasible solution closest to the ideal solution and then ranking set of alternatives, are appropriate and applicable to measuring and assessing issues similar to those that are the focus here. For instance, the technique for order preference by similarity to ideal solution (TOPSIS), elimination and choice expressing reality (ELECTRE), and vise kriterijumska optimisacija kompromisno resenje (VIKOR), preference ranking organization method for enrichment of evaluations (PROMETHEE) can be employed for different MCDM problems (Sharma et al., 2013; Keshavarz et al., 2015; Dhiman et al., 2019; Hamurcu \& Eren, 2019; Pereira et al., 2019). TOPSIS and VIKOR are the more popular and widely used MCDM techniques (Yazdani \& Payam, 2015; Hamurcu \& Eren, 2019). These methods search for a compromise solution that ensures the alternative is closest as possible to the positive ideal solution and the farthest from the negative ideal solution (Hamurcu \& Eren, 2019). The evaluation based on distance from average solution (EDAS) method was proposed by Keshavarz et al. (2015) for ranking alternative based on distances of each alternative from the average solution according to each criterion. The EDAS method is similarly based on verified approaches used in some noticeable MCDM 
methods (Hamurcu \& Eren, 2019). In comparison with existing methods, the EDAS model only considers the average solution for achieving more perfect and efficient aggregation results (Zhang et al., 2019). As such, the EDAS based on Shannon's entropy weight was selected for this study.

In this context, the goal of this study was to provide a Multi-Criteria evaluation framework for insurance performance in OECD countries by investigating conflicting and incommensurate IPIs for the period of 2010-2017. To accomplish this task, a contextual framework was built for identifying IPIs. These IPI were weighted with the help of Shannon's entropy. The OECD insurance industries were also evaluated and ranked using the EDAS method. Sensitivity analysis was performed for different weighted criteria to assess the robustness of the results. Thus, the findings provide three valuable contributions to the literature. First, the findings contribute to the growing literature on the insurance industry in the OECD context, which has not yet been studied extensively. Second, I used a methodological framework based on EDAS with Shannon's entropy weight that considers IPIs in building a list of rankings OECD insurance industries; this methodology provides more consistent results by applying a sensitivity analysis. Third, the results of this research are expected to assist governments and policy makers in insurance organizations in OECD countries.

This paper is organized as follows. Section 2 provides the contextual setting, which includes formal definitions for the IPIs included in the analysis. Section 3 discusses the research methodology. Section 4 presents the empirical evaluation of the application to the OECD insurance industries. Section 5 provides further discussions and outlines the implications of this finding. Section 6 concludes and highlights the research limitations.

\section{Contextual Setting of the IPIs}

In this section, the indicators that reflect the most essential characteristics of the insurance markets in the OECD are presented. These indicators were obtained and selected by analyzing the OECD Insurance Statistics publication (OECD, 2019) and the other documents that are available on OECD websites (https://www.oecd-ilibrary.org and https://www.oecd.org/finance/insurance/).

Those materials provide official information on the diverse insurance activities in OECD countries. The selected IPIs were defined based on the insurance literature (Chen et al., 2001; Wipf \& Garand, 2008; Ma \& Pope, 2008; Pervan \& Kramaric, 2012; Mehari \& Aemiro, 2013; Vojak, 2014; Kwon \& Wolfrom, 2016). The next sections define the IPIs related to official measures of the insurance performance in the OECD countries.

Gross written premiums (GWP): An accurate formulation for GWP, as percentage of the gross domestic product (GDP), only has meaning in the context of the insurance industry. GWP is expressed as the sum of direct and indirect written premiums before the effect of ceded reinsurance is considered, and it is calculated on premiums growth (Pervan \& Kramaric, 2012). Premium growth can be interpreted as a measure of solvency or to what extent the country is capable of increasing revenues. Premium growth (PG) can be calculated in terms of the GWP with the following equation (Pervan \& Kramaric, 2012):

$$
P G_{t}=\frac{G W P_{t}-G W P_{t-1}}{G W P_{t-1}}
$$

where premium growth in year $t$ is given by the value of GWP in the same year minus and divided by the GWP of the previous year.

Reinsurance premiums (RP): Insurance companies usually insure part of their premiums using reinsurance (Wipf \& Garand, 2008). Reinsurance is an insurance contract 
and RP represent the premiums assigned to an amount paid by an insurance company (insurer) to reduce its overall risk exposure, in which some part of its own insurance liabilities is ceded to another insurance company (reinsurer) (Chen et al., 2001)

Net written premiums (NWP) are expressed as the premiums retained by the insurer after the subtraction of the RP paid to local or international reinsurers from GWP. In other words, after RP plus any reinsurance assumed (RA) are deducted from GWP is called NWP (Wipf \& Garand, 2008). NWP indicates of the level of sales for risks that the insurer covers. NWP in year $t$ can be calculated as:

$$
N W P_{t}=G W P_{t}-\left(R P_{t}+R A_{t}\right)
$$

The higher the reinsurance premiums, the lower the potential claims; the higher the reinsurance premiums, the lower the revenues, and vice versa. The reduction in reinsurance premiums that increases revenues simultaneously increases the risk of exposure to potential claims from these premiums.

Gross claims payments (GCP) are the collective of all claims paid throughout an accounting period adjusted by the modification in the claims provision for that accounting period after deducting reinsurance recoveries. The GCP can be used to drive the incurred claims ratio (ICR)/loss ratio (LR) indicator (Wipf \& Garand, 2008), and is discussed in detail below. GCP is calculated by adding paid claims (PC) and unpaid claims (UPC) minus the estimate of unpaid claims (EUPC) at the end of the prior valuation period.

$$
\mathrm{GCP}=(P C+U P C)-E U P C
$$

The number of insurance undertakings (NIU) includes all insurers authorized and licensed in the reporting country containing all professional insurance companies (life, nonlife, composite, reinsurance), but excluding any other scheme of social security controlled by the government.
Insurance density (ID) is a the most commonly used indicator for explaining the level of national insurance and the level of insurance protection (Pervan \& Kramaric, 2012; Mehari \& Aemiro, 2013; Vojak, 2014; Kwon \& Wolfrom, 2016). ID indicates the average annual per capita premium within a country expressed in U.S. dollars and defined as GWP per capita. ID is an indicator of the development of insurance within a country and is calculated as the ratio of GWP (in USD) to total population of a given country and can be used as a proxy for per capita consumption of insurance. ID is expressed as follows (Kwon \& Wolfrom, 2016):

$$
I D=\frac{G W P}{\text { Total Population of the Country }}
$$

ID indicates how much each person in a country spends on insurance in terms of premium. For example, if a country generates a total insurance premium of say, USD $\$ 10$ billion and the population of the that country is 10 million people, the insurance density (per capital premium) would be USD \$1000.

Insurance penetration (IP) is called also insurance spending, indicating the insurance sector level development in a country. It is the second most commonly used indicator applied to analyzing the insurance industry (Pervan \& Kramaric, 2012; Mehari \& Aemiro, 2013; Vojak, 2014; Kwon \& Wolfrom, 2016). This indicator is measured as the real annualized value of total premiums per capita and is calculated as GWP, or premiums at the market level, divided by the total country's GDP (Pervan \& Kramaric, 2012):

$$
I P=\left(\frac{G W P}{G D P}\right) \times 100
$$

IP is a measure of the relative importance of insurance as a component of a country's overall economy. PR is an alternative term used for coverage ratio or participation rate (Wipf \& Garand, 2008). Retention ratio (RR) is one of financial soundness indicators for 
the insurance and reinsurance market. The $\mathrm{RR}$ is used for measuring the underwriting performance of an insurance company. This ratio evaluates the insurance company's success in retaining existing insurance contracts for renewal, or a ratio of the number of contracts renewed to the number of contracts conditional on renewal (Kwon \& Wolfrom, 2016). RR is a measure of how much of the risk is being carried by an insurer rather than being passed to reinsurers (Vojak, 2014). RR is calculated as:

$$
R R=\left(\frac{N W P}{G W P}\right) \times 100
$$

\section{Research Methodology}

Assume $m$ alternatives (countries) $A_{i}(i=$ $1,2 \ldots m)$ are to be assessed against $n$ selection criteria (IPIs) $C_{j}(j=1,2, \ldots n)$. Quantitative values $x_{i j}$ can be assigned to each alternative $A_{i}$, representing the performance of $A_{i}$ with respect to criterion $C_{j}$. $x_{i j}$ is needed to determinate the decision matrix $X=\left\{x_{-} i j, i=1,2 \ldots m ; j=1,2 \ldots n\right\}$ and the weighting vector $W$ represents the relative importance weights of $C_{j}$ selection criteria for the problem.

The decision matrix $\mathrm{X}$ and the weighting vector $\mathrm{W}$ can be expressed as:

$$
\begin{aligned}
X=\begin{array}{c}
C_{1} \\
A_{1} \\
A_{2} \\
\vdots \\
A_{m}
\end{array}\left[\begin{array}{ccccc}
x_{11} & x_{12} & \ldots & C_{n} \\
x_{21} & x_{22} & \ldots & x_{1 n} \\
& \vdots & & \ddots & x_{2 n} \\
x_{m 1} & x_{m 2} & \cdots & x_{m n}
\end{array}\right] \\
W=\left\{w_{1}, w_{2}, \ldots . w_{n}\right\}
\end{aligned}
$$

Given decision matrix $X$ and the weighting vector $\mathrm{W}$, the MCDM method (EDAS based on the Shannon's entropy weight) is applied to prioritize the OECD countries based on selection criteria (their IPIs). To achieve the objective of this study, the IPIs were first weighed through Shannon entropy and then the OECD countries were ranked within EDAS method. In the following sub-sections, these two methods are discussed.

\subsection{Shannon's Entropy}

Shannon introduced the entropy method (also referred to as Shannon's entropy) to information theory for measuring the amount of useful information within the data provided (Shannon, 1948). Shannon's concept uses the entropy measure, which is a well-known method for determining objective weights in MCDM problems (Yoon \& Hwang, 1995; Wang \& Lee, 2009; Gray, 2011). The measure has been widely used in many fields such as social sciences, physics, engineering, mathematics, medicine, economy, finance, and so forth (Gray, 2011).

Shannon entropy was applied in this research for assessing the weights of the insurance indicators for OECD countries. The steps for calculating Shannon's entropy are as follows (Wang \& Lee, 2009).

Step 1: The decision matrix needs to be normalized for each criterion $\mathrm{C}_{-} \mathrm{j}$ for calculating the probability distribution as follows:

$$
p_{i j}=\frac{x_{i j}}{\sum_{i=1}^{m} x_{i j}}
$$

Step 2: The value of entropy $e_{j}$ is calculated as

$$
e_{j}=-h \sum_{i=1}^{m} p_{i j} \ln p_{i j}
$$

where $(\ln (m))^{-1}$ is the entropy constant and $h=(\ln (m))^{-1}$

Step 3: The divergence degree $d_{j}$ of the inherent knowledge of each criterion $C_{j}$ is calculated as:

$$
d_{j}=1-e_{j}
$$

Step 4: The objective weight $\left(w_{i}\right)$ for each criterion $C_{j}$ can be obtained as follows: 


$$
w_{j}=\frac{d_{j}}{\sum_{s=1}^{n} d_{s}} ; j=1,2 \ldots, n
$$

\subsection{EDAS Method}

In the EDAS method, two novel distance measures, the positive distance from average (PDA) and the negative distance from average (NDA), are needed (Keshavarz et al., 2015). These two measures indicate the difference between each alternative and the average solution, and then the alternatives are evaluated according to higher values of the PDA and lower values of the NDA (Keshavarz et al., 2015; Kahraman et al., 2017).

After constructing the decision matrix $\mathrm{X}$, classical EDAS is calculated using the following steps (Keshavarz et al., 2015; Kahraman et al., 2017):

Step 1: Calculate the average solution $\left(A V_{j}\right)$ with respect to all criteria

$$
A V_{j}=\frac{x_{i j}}{\sum_{i=1}^{m} x_{i j}}
$$

Step 2: Compute the PDA and the NDA matrixes with respect to lower and upper values of matrix as shown following formulas.

If the $j$ th criterion is beneficial,

$$
\begin{aligned}
P D A_{i j} & =\frac{\operatorname{MAX}\left(0,\left(x_{i j}-A V_{j}\right)\right)}{A V_{j}} \quad \text { and } \\
N D A_{i j} & =\frac{M A X\left(0,\left(A V_{j}-x_{i j}\right)\right)}{A V_{j}}
\end{aligned}
$$

If the $j$ th criterion is not beneficial,

$$
\begin{aligned}
P D A_{i j} & =\frac{M A X\left(0,\left(A V_{j}-x_{i j}\right)\right)}{A V_{j}} \\
N D A_{i j} & =\frac{M A X\left(0,\left(x_{i j}-A V_{j}\right)\right)}{A V_{j}}
\end{aligned}
$$

where $P D A_{i j}$ and $N D A_{i j}$ denote the positive and negative distance of the $i$ th alternative from average solution in terms of $j$ th criterion for the lower level of decision matrix, respectively.

Step 3: Determine weighted summation of $P D A$ and $N D A$ for all alternatives:

$$
\begin{aligned}
& S P_{i}=\sum_{j=1}^{n} w_{j} P D A_{i j} \\
& S N_{i}=\sum_{j=1}^{n} w_{j} P D A_{i j}
\end{aligned}
$$

Step 4: Normalize the values of $S P$ and $S N$ for all alternatives, as follows:

$$
\begin{gathered}
N S P_{i}=\frac{S P_{i}}{\operatorname{MAX}\left(S P_{i}\right)} \\
N S N_{i}=1-\frac{S N_{i}}{\operatorname{MAX}\left(S N_{i}\right)}
\end{gathered}
$$

Step 5: Determine the appraisal score $(A S)$ for all alternatives:

$$
A S_{i}=\frac{1}{2}\left(N S P_{i}+N S N_{i}\right)
$$

Step 6: Rank the alternatives according to the decreasing values of $A S$. The alternative with the highest $A S$ is the best choice between the candidate alternatives.

\section{Application to the OECD Insurance Industries}

\subsection{Data Collection}

In this study, annual data for the OECD countries for the period 2010-2017 were obtained from the OECD Insurance Statistics publication (OECD, 2019). The publication provides major official information on the various insurance activities in OECD countries. This document has been published annually and available on their website (https://www.oecd-ilibrary.org). According to available data, I used variables in the 20102017 period, including 8 IPIs (Section 2), which reflect the 27 OECD insurance industries to benchmark the international insurance performance of these countries for all type of insurance companies (life, non-life, composite, reinsurance). The 27 countries are 
Australia (AUS), Belgium (BEL), Chile (CHL), Czech Republic (CZE), Denmark (DNK), Finland (FIN), France (FRA), Germany (DEU), Hungary (HUN), Iceland (ISL), Italy (ITA), Japan (JPN), Latvia (LVA), Luxembourg (LUX), Mexico (MEX), Netherlands (NLD), Norway (NOR), Poland (POL), Portugal (PRT), Slovakia (SVK), Slovenia (SVN), Spain (ESP), Sweden (SWE), Switzerland (CHE), Turkey (TUR), the United Kingdom (GBR), the United States (USA). Due to space limitations, Table 1 only shows the raw Multi-Criteria evaluation matrix of the national insurance industry in the 27 OECD countries according to the 8 IPIs in 2017. According to Equation (7), the data in Table 1 were used to create the decision matrix for 27 alternatives (27 OECD countries) with respect to 8 conflict and incommensurate criteria (8 IPIs).

Table 1. The data of 27 OECD countries and IPI in 2017.

\begin{tabular}{|c|c|c|c|c|c|c|c|c|c|}
\hline & \multicolumn{8}{|c|}{ Criterion (IPI) } \\
\hline & & GWP * & $\mathbf{R P} *$ & NWP * & GCP $* *$ & NIU * & ID * & IP * & $\mathbf{R R} *$ \\
\hline & & $\begin{array}{c}\text { (Million } \\
\text { USD) }\end{array}$ & $\begin{array}{c}\text { (Million } \\
\text { USD) }\end{array}$ & $\begin{array}{c}\text { (Million } \\
\text { USD) }\end{array}$ & $\begin{array}{c}\text { (Million } \\
\text { USD) }\end{array}$ & (n) & $\begin{array}{c}\text { (Million } \\
\text { USD) }\end{array}$ & $(\%)$ & $(\%)$ \\
\hline \multirow{27}{*}{ 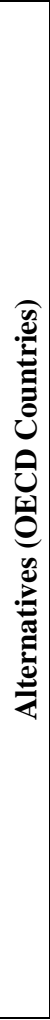 } & AUS & $72,339.1$ & 9959 & 24,712 & 61,603 & 125 & 2541 & 4.444 & 77 \\
\hline & BEL & $30,762.9$ & 3508 & 10,749 & 30,449 & 114 & 2647 & 6.073 & 88 \\
\hline & CHL & $12,860.5$ & 1468 & 2462 & 9950 & 69 & 693 & 4.599 & 83 \\
\hline & CZE & 6401.6 & 1161 & 2786 & 3881 & 49 & 590 & 2.891 & 79 \\
\hline & DNK & $37,549.3$ & 1177 & 10,428 & 24,022 & 156 & 6315 & 11.006 & 97 \\
\hline & FIN & $10,058.6$ & 229 & 4727 & 8353 & 47 & 1798 & 3.923 & 97 \\
\hline & FRA & $313,542.5$ & 25,730 & 114,636 & 277,873 & 631 & 4225 & 10.602 & 88 \\
\hline & DEU & $310,439.2$ & 35,819 & 175,098 & 173,383 & 368 & 2829 & 6.336 & 87 \\
\hline & HUN & 3483.6 & 417 & 1387 & 2165 & 40 & 350 & 2.456 & 87 \\
\hline & ISL & 611 & 17 & 540 & 426 & 8 & 1772 & 2.46 & 96 \\
\hline & ITA & $150,359.4$ & 4861 & 34,521 & 106,946 & 213 & 2431 & 7.576 & 96 \\
\hline & JPN & $390,095.6$ & 21,111 & 75,969 & 315,183 & 93 & 2893 & 7.428 & 90 \\
\hline & LVA & 727.9 & 49 & 515 & 407 & 17 & 373 & 2.389 & 93 \\
\hline & LUX & $24,253.9$ & 643 & 1348 & 14,690 & 291 & 41,011 & 38.829 & 86 \\
\hline & MEX & $26,568.8$ & 4423 & 10,725 & 13,392 & 115 & 211 & 2.254 & 81 \\
\hline & NLD & $80,266.2$ & 1247 & 63,410 & 87,371 & 140 & 4615 & 9.49 & 98 \\
\hline & NOR & $20,406.6$ & 860 & 7254 & 12,966 & 100 & 3858 & 5.108 & 93 \\
\hline & POL & $16,498.6$ & 1865 & 8135 & 10,542 & 61 & 420 & 3.034 & 88 \\
\hline & PRT & $12,909.1$ & 1211 & 4136 & 10,798 & 73 & 1186 & 5.573 & 89 \\
\hline & SVK & 5035 & 359 & 862 & 217 & 38 & 925 & 5.254 & 92 \\
\hline & SVN & 2589.6 & 329 & 1680 & 1773 & 21 & 1102 & 4.67 & 86 \\
\hline & ESP & $74,058.2$ & 5731 & 35,147 & 55,508 & 220 & 1470 & 5.181 & 91 \\
\hline & SWE & $44,382.3$ & 1160 & 9461 & 16,730 & 203 & 4248 & 8.027 & 97 \\
\hline & CHE & $67,772.5$ & 4815 & 32,472 & 52,032 & 192 & 6904 & 8.562 & 93 \\
\hline & TUR & $13,074.1$ & 3534 & 7358 & 6120 & 63 & 152 & 1.444 & 72 \\
\hline & GBR & $394,100.4$ & 35,008 & 89,835 & 417,974 & 294 & 5112 & 12.801 & 88 \\
\hline & USA & $2,836,293.2$ & 586,502 & $1,240,381$ & $1,646,030$ & 4396 & 6706 & 11.215 & 71 \\
\hline
\end{tabular}

* Beneficial criterion. ** Non-beneficial criterion. Source: OECD Insurance Statistics Database.

\subsection{Data Analysis and Results}

In this section, the EDAS based on the Shannon's entropy weight is applied to a Multi-Criteria evaluation process of the national insurance industry in 27 OECD countries according to 8 IPI for 2010 until 2017. According to EDAS procedure based on the Shannon's entropy weight, the weights for all IPI were defined by the entropy method as discussed in Section 3.1. 
Table 2 (see Appendix) shows the Shannon's entropy weighting results for the objective weights and prioritizes all the IPI from 2010 to 2017. The obtained objective weights and their rankings in descending order are presented in Table 2. The obtained Shannon's entropy weights show that RP, NWP, and GWP were rated more important than the remaining criteria in 2010 and 2014-2017. GCP is shown to be the most important criterion followed by RP and NWP and in 2011 and 2012. ID, IP, and RR were rated relatively lower.

After obtaining IPI weights, the next step was to rank the insurance industries of the 27 OECD countries on the basis of these criteria weights using the EDAS method. The raw Multi-Criteria evaluation matrix of the national insurance industry in the 27 OECD countries on the basis of the 8 IPIs in 2010
2017 and the weights obtained for all IPI were used for applying the EDAS method through Equations (13)-(18). The computed results of the 27 OECD countries ranked using the EDAS method between 2010 to 2017 are presented in Table 3 (Appendix). Figure 1 depicts the measurements of the insurance industries' performance in OECD countries in the period 2010-2017 obtained by applying the proposed method. According to the findings, the American insurance industry performed the best according to the IPIs, while the worst performing was Latvia. The top five ranking are the United States, the United Kingdom, Germany, France, and Japan. The bottom five ranking countries are Latvia, Turkey, Slovakia, Hungary, and Iceland except in 2017. In 2017, the five worstperforming insurance industries were Latvia, Turkey, Czech Republic, Hungary, and Iceland.

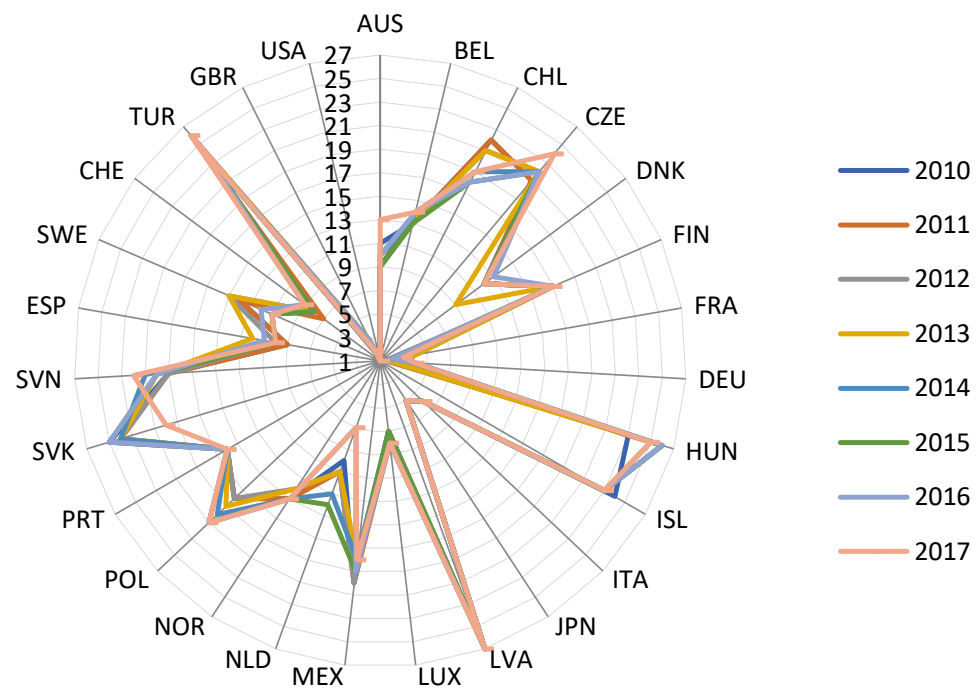

Figure 1. OECD insurance industries rankings for 2010-2017.

The ranking alternatives (insurance industries OECD countries) for the case being may provide a basis for classifying the countries into groups with similar levels of performance. This classification identifies which countries' insurance industries are performing at a similar level according to the
IPI indicators. In this regard, a classification system established using the mean and standard deviation of the ranking values for all alternatives ([AS $\rrbracket$ i $\mathrm{i}$ ) using EDAS based on the Shannon's entropy weight is appropriate in such situations (Ture, Dogan \& Kocak, 2019): 
I. Group 1: Highly efficient performance, if $A S_{i} \geq M A S_{i}+S A S_{i}$

II. Group 2: Medium-high efficiency, if $M A S_{i}+S A S_{i}>A S_{i} \geq M A S_{i}$

III. Group 3: Medium-low efficiency, if $M A S_{i}>A S_{i} \geq M A S_{i}-S A S_{i}$

IV. Group 4: Low efficiency performance, if $A S_{i}<M A S_{i}-S A S_{i}$

where $M A S_{i}$ is the mean value of the overall measured values of $A S_{i}$ obtained by EDAS based on the Shannon's entropy weight and $S A S_{i}$ is the standard deviation of the overall measure values of $A S_{i}$. The classifications of the insurance industries in the selected OECD countries during 2010-2017 are presented in Table 4 (see Appendix).

\subsection{Sensitivity Analysis}

Sensitivity analysis was adopted to assess the robustness of the results obtained from the proposed method. Thus, one-way sensitivity analysis was conducted by changing the weight of one criterion from 0.1 to 0.9 at time and dividing its remaining criterion weight from one into the other criterion through formulating proportional to their original weights. By applying this process, the effects of the changes on country rankings and classifications into groups of similar levels of performance were observed. All scenarios were generated using MATLAB software (The MathWorks, Inc., USA). To save space, one-way sensitivity analysis with changing weights for the RP criterion, one of the most relative important criterions, is only detailed for 2017. The obtained results for this scenario are provided in Figure 2 and Table 5 (see Appendix). According to the results in Figure 2 and Table 4, the first four ranking countries with the best insurance industry performance remained same in this scenario: the United States, the United Kingdom, Germany, and France.

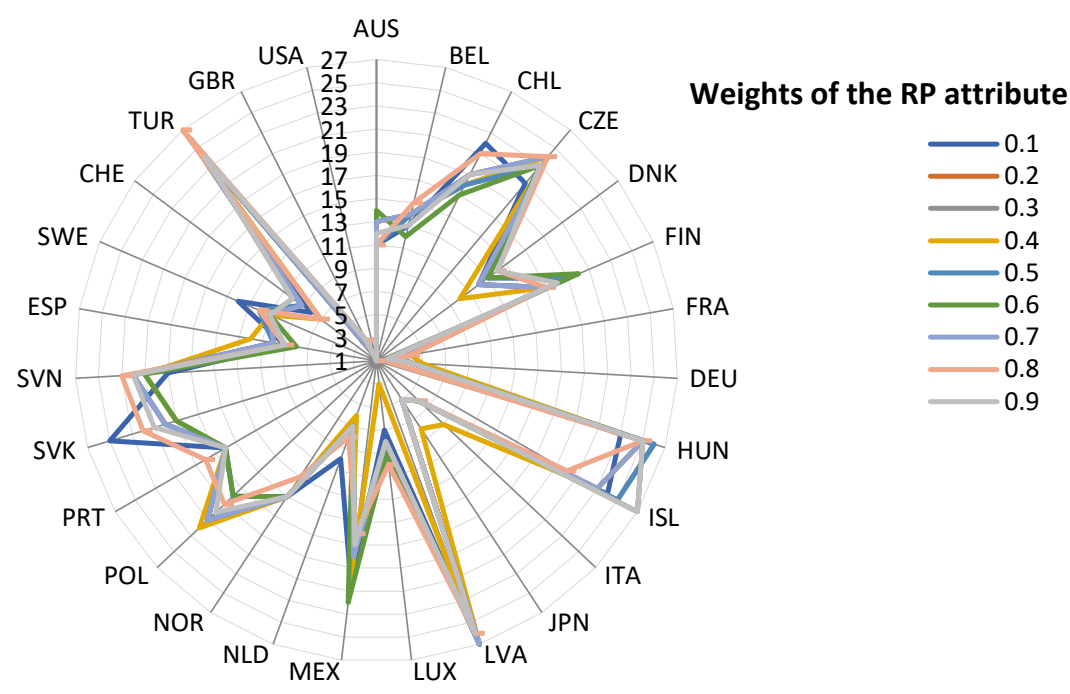

Figure 2. Sensitivity analysis on changing weights of the RP criterion in 2017

By applying all scenarios, the top four ranked countries remained the same in all tests. Although the order ranking for the remaining countries slightly change, those countries were all categorized into the same levels of performance. This suggests that the main empirical results are robust. 


\section{Discussions and Implications}

Some of the results presented in Section 4 have implications for ranking of insurance industries in OECD countries based on IPIs in 2010-2017. The results show that the RP criterion has the highest weight coefficient (24\%) in 2010 and 2014-2017 and the second highest weight coefficient at $11 \%$ and $16 \%$ in 2011 and 2012, respectively. These results indicate that mitigating risk via reinsurance is crucial to protecting insurance industries from financial ruin. The next indicator with the second highest weight coefficient (around $17 \%$ to $19 \%$ ) is NWP in 2010 and 2014-2017, which had the third highest weight coefficients of 7\% and $11 \%$ in 2011 and 2012, respectively. Generally, GWP had the third highest weight coefficient, ranging from $15 \%$ to $16 \%$ in 2010 and 2014-2017, and was ranked the fourth highest at $7 \%$ and $11 \%$ in 2011 and 2012, respectively. NWP and GWP logically remains slightly high as when these two indicators increase, they indicate the expected returns from investment in insurance industries. Thus, RP, NWP, and GWP are considered the most effective of the IPIs in the 27 OECD countries.

Most importantly, the results indicate that, in general, the United States, the United Kingdom, Germany, France, and Japan were top ranked during 2010-2017. A possible explanation for this finding is that these industrialized countries have strong economies and a high economic growth rate. Similar results were reported by Arena (2008), Chen et al. (2012), and Pradhan et al. (2015). They examined the relationship among insurance and economic growth and concluded that insurance activity promotes economic growth and vice versa. Another possible reason for the obtained ranking results is related to the country's insurance improvement level. The insurance in countries such as the United States, the United Kingdom, France, and Germany have undergone many reforms and several changes, especially transitioning health insurance toward national accountability and financial stability (Yaya \& Danhoundo, 2015). In contrast, the lowest ranked countries during 2010-2017 were Latvia, Turkey, Hungary, and Iceland. Thus, the insurance policies implemented in those countries may be inefficient. At this point, these countries need to strengthen their insurance industry by reforming insurance policies.

The classification the OECD countries into groups of similar performance levels should be noted. According to obtained results in Table 4 (Appendix), the group containing the United States, the United Kingdom, Germany, and France showed a high level of performance during 2010-2017. This result is imputed to their competitive and strong national insurance industries and entrepreneurship. Japan was classified in the high level group in 2010-2012 and 2016, and in the medium-high level group in the remaining years. The classification of the rest of the OECD countries varied between the medium-high, medium-low, and low levels during 2010-2017. This lack of variation might be due to the IPIs, financial systems, economic growth, political environments, and environments of the national insurance institutions in these countries as discussed by Pradhan et al. (2015) and Lee et al. (2016). Another factor affecting the variation between performance level groups is the nature of the phases of insurance market development (e.g., developed, emerging, and developing). Most of the countries (around 14-17 countries) were classified as medium-low performance in 2010-2017. In most cases, these are countries considered less developed or developing.

The sensitivity analysis result showed that United States, the United Kingdom, Germany, and France are the best alternatives in all cases. This finding supports the published literature about the positive influence of economic growth rates on insurance industry performance (Arena, 2008; Chen et al., 2012; Pradhan et al., 2015; Pradhan et al., 2017). Although sensitivity analysis produced 
consistent results in terms of the level of performance, the ranking of the countries changed in the medium-low level of insurance performance. A possible explanation reason for this finding is the instability of the insurance sector performance in those countries, indicating the need for these countries to consider the countries with a high level of insurance performance (the United States, the United Kingdom, Germany, and France) as a benchmark to improve and reform their insurance systems.

The methodological framework in this paper can provide a benchmarking tool for governments and policymakers in the insurance field to assist with identifying the most efficient policies and strategies for their insurance industries. This benchmarking tool provides standards for improving poorly performing insurance systems. In this research, the benchmarking tool assists with ranking the leading countries in insurance as a benchmark for other less countries in insurance that desire to overcome some obstacles affecting their insurance performance. The empirical findings in this research provide an important direction for the governments that should prioritize modification of strategic regulations and composing new policies to reinforce insurance industry as part of a competitive economy.

\section{Conclusions}

The aim of this study was to provide a MultiCriteria evaluation framework for ranking the insurance performance of OECD countries by considering conflicting and incommensurate IPIs for the period of 2010-2017. To identify the IPIs, this paper provides a contextual setting framework that reflects the essential characteristics of the insurance markets in the OECD. IPIs were weighted and prioritized using Shannon's entropy. Correspondingly, the entropy weight of the IPIs provided the data for calculating the ranking of the performance of the insurance industries in the 27 OECD in 2010-2017. The outranking method called the EDAS method was applied. The efficiency of the insurance industries of the 27 OECD countries were characterized into groups of high, medium-high, mediumlow, and low to assist with understanding the ranking orders. Finally, sensitivity analysis considering different weighting criteria was conducted to assess the robustness of the results.

The results revealed that the industrialized countries (the United States, the United Kingdom, Germany, France, and Japan) that have high economic growth rates are were ranked at the top and insurance performance was highly efficient during 2010-2017. In accordance with these study findings, the performance of the insurance industries in the less developed countries in the OECD (Table 4, Appendix) was classified as medium-low during 2010-2017. These countries could benefit from the experience and best practices of countries with higher levels of insurance performance. The methodology and finding proposed here could provide a source of guidance for governments and policymakers for the conduct and reform of insurance policies to reinforce the insurance industry to help create a competitive economy in the context of comparable countries.

Future research should focus on ranking insurance industries in OECD countries using the same data set in an uncertain environment. Thus, determining different criteria based on experts' judgment (which is considered uncertain judgment) and assigning the weights of criteria as subjective weights can be examined in future research. Different fuzzy multi-criteria outranking techniques for uncertain environment can be applied in future research.

Funding: The author received direct funding for this research from the Deanship of Scientific Research at King Faisal University 


\section{References:}

Arena, M. (2008). Does insurance market activity promote economic growth? A cross-country study for industrialized and developing countries. Journal of Risk and Insurance, 75(4), 921946.

Chen, P. F., Lee, C. C., \& Lee, C. F. (2012). How does the development of the life insurance market affect economic growth? Some international evidence. Journal of International Development, 24(7), 865-893.

Chen, Y., Hamwi, I. S., \& Hudson, T. (2001). The effect of ceded reinsurance on solvency of primary insurers. International Advances in Economic Research, 7(1), 65-82.

Danesh, D., Ryan, M. J., \& Abbasi, A. (2018). Multi-criteria decision-making methods for project portfolio management: a literature review. International Journal of Management and Decision Making, 17(1), 75-94.

Dhiman, H. S., Deb, D., Muresan, V., \& Unguresan, M. L. (2019). Multi-Criteria Decision Making Approach for Hybrid Operation of Wind Farms. Symmetry, 11(5), 675.

Gray, R. (2011). Entropy and Information Theory Springer: Berlin, Germany.

Haiss, P., \& Sümegi, K. (2008). The relationship between insurance and economic growth in Europe: a theoretical and empirical analysis. Empirica, 35(4), 405-431.

Hamurcu, M., \& Eren, T. (2019). An Application of Multicriteria Decision-making for the Evaluation of Alternative Monorail Routes. Mathematics, 7(1), 16.

Kahraman, C., Keshavarz Ghorabaee, M., Zavadskas, E. K., Cevik Onar, S., Yazdani, M., \& Oztaysi, B. (2017). Intuitionistic fuzzy EDAS method: an application to solid waste disposal site selection. Journal of Environmental Engineering and Landscape Management, 25(1), 112.

Keshavarz Ghorabaee, M., Zavadskas, E. K., Olfat, L., \& Turskis, Z. (2015). Multi-criteria inventory classification using a new method of evaluation based on distance from average solution (EDAS). Informatica, 26(3), 435-451.

Kwon, W. J., \& Wolfrom, L. (2017). Analytical tools for the insurance market and macroprudential surveillance. OECD Journal: Financial Market Trends, 2016(1), 1-47.

Lee, C. C. (2011). Does insurance matter for growth: Empirical evidence from OECD countries. The BE Journal of Macroeconomics, 11(1).

Lee, C. C., Chang, C. H., Arouri, M., \& Lee, C. C. (2016). Economic growth and insurance development: The role of institutional environments. Economic Modelling, 59, 361-369.

Ma, Y. L., \& Pope, N. (2008). Foreign share, insurance density, and penetration: An analysis of the international life insurance market. Risk Management and Insurance Review, 11(2), 327347.

Mehari, D., \& Aemiro, T. (2013). Foreign share, insurance density, and penetration: An analysis of the international life insurance market. European Scientific Journal, 9(10).

OECD. Global Insurance Market Trends' OECD; OECD: Paris, France, 2019. Available online: https://www.oecd.org/daf/fin/insurance/Global-Insurance-Market-Trends-2018.pdf (accessed on, March 2019).

OECD. Insurance Statistics; OECD Publishing: Paris, France, 2018; doi:10.1787/g2g9fad8-en. 
Pereira, T., Ferreira, F. A., \& Araújo, C. (2019). A multicriteria decision model for the selection of information system for a logistics company using MMASSI/TI. International Journal for Quality Research, 13(4), 837-848.

Pervan, M., \& Kramaric, T. P. (2012). Effects of Market Share and Diversification on Nonlife Insurers' Performance. World Academy of Science, Engineering and Technology.

Ponsiglione, C., Nenni, M. E., Castellano, G., \& Molisso, A. (2018). International Journal of Industrial Engineering and Management (IJIEM), 9(1), 43-51.

Pradhan, R. P., Arvin, M. B., \& Norman, N. R. (2015). Insurance development and the financegrowth nexus: Evidence from 34 OECD countries. Journal of Multinational Financial Management, 31, 1-22.

Pradhan, R. P., Dash, S., Maradana, R. P., Jayakumar, M., \& Gaurav, K. (2017). Insurance market density and economic growth in Eurozone countries: the granger causality approach. Financial Innovation, 3(1), 17.

Shannon, C. E. (1948). A mathematical theory of communication. Bell system technical journal, 27(3), 379-423.

Sharma, P., Thakar, G., \& Gupta, R. C. (2013). Evaluation of Assembly Line Balancing Methods Using an Analytical Hierarchy Process (Ahp) and Technique for Order Preferences by Similarity to Ideal Solution (Topsis) Based Approach. International Journal for Quality Research, 7(4), 523-544.

Triantaphyllou, E. (2000). Multi-CriteriaDecision Making Methods: A Comparative Study. Kluwer Academic Publishers: Boston, MA, USA.

Ture, H., Dogan, S., \& Kocak, D. (2019). Assessing Euro 2020 Strategy Using Multi-criteria Decision Making Methods: VIKOR and TOPSIS. Social Indicators Research, 142(2), 645665.

Vojak, N. (2014). Measuring financial soundness od insurance companies by using CARAMELS model-case of Croatia. Interdiscip. Manag. Res., 10, 600-609.

Wang, T. C., \& Lee, H. D. (2009). Developing a fuzzy TOPSIS approach based on subjective weights and objective weights. Expert systems with applications, 36(5), 8980-8985.

Ward, D., \& Zurbruegg, R. (2000). Does insurance promote economic growth? Evidence from OECD countries. Journal of Risk and Insurance, 489-506.

Wipf, J., \& Garand, D. (2008). Performance indicators for microinsurance. A handbook for microinsurance practitioners. CGAP Working Group on Microinsurance, ADA and BRS.

Yaya, S., \& Danhoundo, G. (2015). Introduction: special issue on innovations in health care system reform in OECD countries. The Innovation Journal, 20(1), 1.

Yazdani, M., \& Payam, A. F. (2015). A comparative study on material selection of microelectromechanical systems electrostatic actuators using Ashby, VIKOR and TOPSIS. Materials \& Design, 65, 328-334.

Yoon, K. P., \& Hwang, C. L. (1995). Multiple attribute decision making: an introduction (Vol. 104). Sage publications.

Zhang, S., Gao, H., Wei, G., Wei, Y., \& Wei, C. (2019). Evaluation based on distance from average solution method for multiple criteria group decision making under picture 2-tuple linguistic environment. Mathematics, 7(3), 243. 


\section{Tarifa S. Almulhim}

School of Business,

King Faisal University,

Al-Ahsa 31982,

Saudi Arabia

talmulhim@kfu.edu.sa 


\section{Appendix}

Table 2. Shannon's entropy weights

\begin{tabular}{|c|c|c|c|c|c|c|c|c|c|}
\hline & \multicolumn{8}{|c|}{ Year } \\
\hline & & \multicolumn{2}{|c|}{2010} & \multicolumn{2}{|c|}{2011} & \multicolumn{2}{|c|}{2012} & \multicolumn{2}{|c|}{2013} \\
\hline & & Weight & Rank & Weight & Rank & Weight & Rank & Weight & Rank \\
\hline \multirow{8}{*}{ 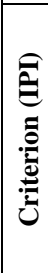 } & GWP & 0.1536 & 3 & 0.0732 & 4 & 0.1054 & 4 & 0.1556 & 3 \\
\hline & $\mathbf{R P}$ & 0.247 & 1 & 0.1114 & 2 & 0.1611 & 2 & 0.2442 & 1 \\
\hline & NWP & 0.1715 & 2 & 0.0798 & 3 & 0.1144 & 3 & 0.1819 & 2 \\
\hline & GCP & 0.145 & 4 & 0.6223 & 1 & 0.4376 & 1 & 0.1428 & 4 \\
\hline & NIU & 0.1293 & 5 & 0.0614 & 5 & 0.0887 & 5 & 0.1392 & 5 \\
\hline & ID & 0.1106 & 6 & 0.0387 & 6 & 0.0672 & 6 & 0.1008 & 6 \\
\hline & IP & 0.0428 & 7 & 0.0131 & 7 & 0.0254 & 7 & 0.0352 & 7 \\
\hline & RR & 0.0002 & 8 & 0.0001 & 8 & 0.0002 & 8 & 0.0003 & 8 \\
\hline & & \multicolumn{8}{|c|}{ Year } \\
\hline & & \multicolumn{2}{|c|}{2014} & \multicolumn{2}{|c|}{2015} & \multicolumn{2}{|c|}{2016} & \multicolumn{2}{|c|}{2017} \\
\hline & & Weight & Rank & Weight & Rank & Weight & Rank & Weight & Rank \\
\hline \multirow{8}{*}{ 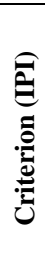 } & GWP & 0.1564 & 3 & 0.1681 & 3 & 0.1564 & 3 & 0.1681 & 3 \\
\hline & RP & 0.2426 & 1 & 0.2425 & 1 & 0.2426 & 1 & 0.2425 & 1 \\
\hline & NWP & 0.1823 & 2 & 0.1868 & 2 & 0.1823 & 2 & 0.1868 & 2 \\
\hline & GCP & 0.14 & 5 & 0.1489 & 4 & 0.14 & 5 & 0.1489 & 4 \\
\hline & NIU & 0.1405 & 4 & 0.1354 & 5 & 0.1405 & 4 & 0.1354 & 5 \\
\hline & ID & 0.1021 & 6 & 0.0875 & 6 & 0.1021 & 6 & 0.0875 & 6 \\
\hline & IP & 0.0358 & 7 & 0.0305 & 7 & 0.0358 & 7 & 0.0305 & 7 \\
\hline & $\mathbf{R R}$ & 0.0003 & 8 & 0.0003 & 8 & 0.0003 & 8 & 0.0003 & 8 \\
\hline
\end{tabular}

Table 3. Rankings based on EDAS method

\begin{tabular}{|c|c|c|c|c|c|c|c|c|c|}
\hline & \multicolumn{8}{|c|}{ Year } \\
\hline & & \multicolumn{2}{|c|}{2010} & \multicolumn{2}{|c|}{2011} & \multicolumn{2}{|c|}{2012} & \multicolumn{2}{|c|}{2013} \\
\hline & & AS & Rank & AS & Rank & AS & Rank & AS & Rank \\
\hline \multirow{27}{*}{ 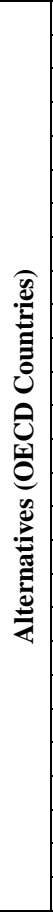 } & AUS & 0.24345 & 11 & 0.2652 & 10 & 0.27682 & 9 & 0.27536 & 10 \\
\hline & BEL & 0.21315 & 13 & 0.20719 & 13 & 0.21221 & 13 & 0.20088 & 13 \\
\hline & CHL & 0.041627 & 22 & 0.045514 & 22 & 0.05384 & 21 & 0.054274 & 21 \\
\hline & CZE & 0.047153 & 21 & 0.048023 & 21 & 0.042075 & 22 & 0.042597 & 22 \\
\hline & DNK & 0.22186 & 12 & 0.21269 & 12 & 0.21442 & 12 & 0.27999 & 9 \\
\hline & FIN & 0.095491 & 17 & 0.082119 & 17 & 0.068251 & 17 & 0.096283 & 17 \\
\hline & FRA & 0.49923 & 3 & 0.49768 & 4 & 0.49023 & 4 & 0.50103 & 4 \\
\hline & DEU & 0.49596 & 4 & 0.50456 & 2 & 0.49959 & 3 & 0.51199 & 2 \\
\hline & HUN & 0.025227 & 23 & 0.021766 & 25 & 0.015112 & 26 & 0.016544 & 26 \\
\hline & ISL & 0.024195 & 24 & 0.026652 & 23 & 0.023112 & 23 & 0.021911 & 23 \\
\hline & ITA & 0.38187 & 6 & 0.34903 & 6 & 0.34969 & 6 & 0.35618 & 6 \\
\hline & JPN & 0.46871 & 5 & 0.48345 & 5 & 0.465 & 5 & 0.43169 & 5 \\
\hline & LVA & 0.00033511 & 27 & 0.00041363 & 27 & 0.00044936 & 27 & 0.00057475 & 27 \\
\hline & LUX & 0.33041 & 7 & 0.28269 & 8 & 0.31224 & 7 & 0.31177 & 7 \\
\hline & MEX & 0.050334 & 20 & 0.049649 & 20 & 0.054868 & 20 & 0.063412 & 18 \\
\hline & NLD & 0.24978 & 10 & 0.25833 & 11 & 0.24155 & 11 & 0.26259 & 11 \\
\hline & NOR & 0.14467 & 15 & 0.15448 & 15 & 0.16802 & 14 & 0.1638 & 14 \\
\hline & POL & 0.062573 & 18 & 0.063848 & 18 & 0.062306 & 18 & 0.05669 & 19 \\
\hline & PRT & 0.13361 & 16 & 0.10969 & 16 & 0.099795 & 16 & 0.11695 & 16 \\
\hline & SVK & 0.024097 & 25 & 0.023706 & 24 & 0.019972 & 24 & 0.020536 & 24 \\
\hline & SVN & 0.055937 & 19 & 0.062042 & 19 & 0.057187 & 19 & 0.056531 & 20 \\
\hline & ESP & 0.26904 & 9 & 0.26894 & 9 & 0.25346 & 10 & 0.25887 & 12 \\
\hline & SWE & 0.17074 & 14 & 0.1692 & 14 & 0.14957 & 15 & 0.16032 & 15 \\
\hline & CHE & 0.28941 & 8 & 0.28777 & 7 & 0.30356 & 8 & 0.30751 & 8 \\
\hline & TUR & 0.016805 & 26 & 0.0097117 & 26 & 0.015878 & 25 & 0.018418 & 25 \\
\hline & GBR & 0.52275 & 2 & 0.50436 & 3 & 0.51316 & 2 & 0.50843 & 3 \\
\hline & USA & 0.98744 & 1 & 0.9876 & 1 & 0.98771 & 1 & 0.98481 & 1 \\
\hline
\end{tabular}


Table 3. Rankings based on EDAS method (continued)

\begin{tabular}{|c|c|c|c|c|c|c|c|c|c|}
\hline & \multicolumn{8}{|c|}{ Year } \\
\hline & & \multicolumn{2}{|c|}{2014} & \multicolumn{2}{|c|}{2015} & \multicolumn{2}{|c|}{2016} & \multicolumn{2}{|c|}{2017} \\
\hline & & $\mathbf{A S}$ & Rank & $\mathbf{A S}$ & Rank & $\mathbf{A S}$ & Rank & $\mathbf{A S}$ & Rank \\
\hline \multirow{27}{*}{ 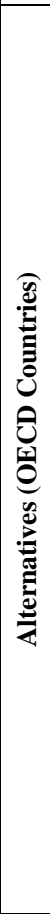 } & AUS & 0.28852 & 9 & 0.25653 & 9 & 0.23517 & 10 & 0.20236 & 13 \\
\hline & BEL & 0.19518 & 14 & 0.18209 & 13 & 0.17427 & 14 & 0.15949 & 14 \\
\hline & CHL & 0.048505 & 19 & 0.059857 & 18 & 0.065185 & 18 & 0.055524 & 19 \\
\hline & CZE & 0.034797 & 22 & 0.028356 & 22 & 0.02614 & 22 & 0.019662 & 24 \\
\hline & DNK & 0.21659 & 12 & 0.20561 & 12 & 0.2084 & 13 & 0.20792 & 12 \\
\hline & FIN & 0.095321 & 17 & 0.095362 & 17 & 0.076622 & 17 & 0.066062 & 17 \\
\hline & FRA & 0.50227 & 3 & 0.50204 & 2 & 0.51654 & 2 & 0.52054 & 3 \\
\hline & DEU & 0.49517 & 4 & 0.492 & 4 & 0.48951 & 4 & 0.48701 & 4 \\
\hline & HUN & 0.012841 & 26 & 0.0099201 & 26 & 0.013757 & 26 & 0.0092207 & 25 \\
\hline & ISL & 0.017479 & 23 & 0.019887 & 23 & 0.023376 & 23 & 0.025988 & 23 \\
\hline & ITA & 0.35788 & 6 & 0.35512 & 6 & 0.32824 & 6 & 0.31967 & 6 \\
\hline & JPN & 0.4174 & 5 & 0.416 & 5 & 0.45306 & 5 & 0.4249 & 5 \\
\hline & LVA & 0.00056633 & 27 & 0.00050334 & 27 & 0.0005299 & 27 & 0.00034642 & 27 \\
\hline & LUX & 0.31053 & 7 & 0.29628 & 7 & 0.29207 & 8 & 0.29868 & 8 \\
\hline & MEX & 0.058678 & 18 & 0.054627 & 19 & 0.053654 & 19 & 0.055772 & 18 \\
\hline & NLD & 0.20864 & 13 & 0.17574 & 14 & 0.31564 & 7 & 0.31286 & 7 \\
\hline & NOR & 0.16271 & 15 & 0.15445 & 15 & 0.15971 & 15 & 0.14344 & 15 \\
\hline & POL & 0.047595 & 20 & 0.043489 & 21 & 0.043954 & 21 & 0.044737 & 21 \\
\hline & PRT & 0.11765 & 16 & 0.10906 & 16 & 0.090046 & 16 & 0.082764 & 16 \\
\hline & SVK & 0.015798 & 24 & 0.011271 & 25 & 0.01754 & 25 & 0.049945 & 20 \\
\hline & SVN & 0.047046 & 21 & 0.048223 & 20 & 0.049053 & 20 & 0.04124 & 22 \\
\hline & ESP & 0.24754 & 10 & 0.22894 & 10 & 0.23316 & 11 & 0.2201 & 10 \\
\hline & SWE & 0.22769 & 11 & 0.21461 & 11 & 0.20923 & 12 & 0.21118 & 11 \\
\hline & CHE & 0.30261 & 8 & 0.29622 & 8 & 0.28503 & 9 & 0.2788 & 9 \\
\hline & TUR & 0.013267 & 25 & 0.011919 & 24 & 0.018054 & 24 & 0.0086829 & 26 \\
\hline & GBR & 0.50425 & 2 & 0.50171 & 3 & 0.51583 & 3 & 0.53053 & 2 \\
\hline & USA & 0.98832 & 1 & 0.98628 & 1 & 0.98618 & 1 & 0.98496 & 1 \\
\hline
\end{tabular}

Table 4. Groups of OECD countries with similar levels of insurance performance according to IPIs

\begin{tabular}{|c|c|c|c|c|c|}
\hline & \multicolumn{4}{|c|}{ Level of Efficient Performance } \\
\hline & & High & Medium-High & Medium-Low & Low \\
\hline \multirow{8}{*}{$\stackrel{\varpi}{\nexists}$} & 2010 & $\begin{array}{l}\text { FRA, DEU, JPN, } \\
\text { GBR, USA }\end{array}$ & $\begin{array}{l}\text { AUS, ITA, LUX, NLD, } \\
\text { ESP, CHE }\end{array}$ & $\begin{array}{c}\text { BEL, CHL, CZE, DNK, FIN, HUN, ISL, } \\
\text { LVA, MEX, NOR, POL, PRT, SVK, } \\
\text { SVN, SWE, TUR }\end{array}$ & / \\
\hline & 2011 & $\begin{array}{l}\text { FRA, DEU, JPN, } \\
\text { GBR, USA }\end{array}$ & $\begin{array}{l}\text { AUS, ITA, LUX, NLD, } \\
\text { ESP, CHE }\end{array}$ & $\begin{array}{c}\text { BEL, CHL, CZE, DNK, FIN, HUN, ISL, } \\
\text { LVA, MEX, NOR, POL, PRT, SVK, } \\
\text { SVN, SWE, TUR }\end{array}$ & I \\
\hline & 2012 & $\begin{array}{l}\text { FRA, DEU, JPN, } \\
\text { GBR, USA }\end{array}$ & $\begin{array}{l}\text { AUS, ITA, LUX, NLD, } \\
\text { ESP, CHE }\end{array}$ & $\begin{array}{c}\text { BEL, CHL, CZE, DNK, FIN, HUN, ISL, } \\
\text { LVA, MEX, NOR, POL, PRT, SVK, } \\
\text { SVN, SWE, TUR }\end{array}$ & l \\
\hline & 2013 & $\begin{array}{l}\text { FRA, DEU, GBR, } \\
\text { USA }\end{array}$ & $\begin{array}{l}\text { AUS, DNK, ITA, JPN, } \\
\text { LUX, NLD, ESP, CHE }\end{array}$ & $\begin{array}{l}\text { BEL, CHL, CZE, FIN, HUN, ISL, MEX, } \\
\text { NOR, POL, PRT, SVK, SVN, SWE, TUR }\end{array}$ & LVA \\
\hline & 2014 & $\begin{array}{l}\text { FRA, DEU, GBR, } \\
\text { USA }\end{array}$ & $\begin{array}{l}\text { AUS, ITA, JPN, LUX, } \\
\text { NLD, ESP, SWE, CHE }\end{array}$ & $\begin{array}{c}\text { BEL, CHL, CZE, FIN, HUN, ISL, LVA, } \\
\text { MEX, NLD, NOR, POL, PRT, SVK, } \\
\text { SVN, TUR }\end{array}$ & I \\
\hline & 2015 & $\begin{array}{l}\text { FRA, DEU, GBR, } \\
\text { USA }\end{array}$ & $\begin{array}{l}\text { AUS, ITA, JPN, LUX, } \\
\text { ESP, SWE, CHE }\end{array}$ & $\begin{array}{c}\text { BEL, CHL, CZE, DNK, FIN, HUN, ISL, } \\
\text { LVA, MEX, NLD, NOR, POL, PRT, } \\
\text { SVK, SVN, TUR }\end{array}$ & / \\
\hline & 2016 & $\begin{array}{l}\text { FRA, DEU, JPN, } \\
\text { GBR, USA }\end{array}$ & $\begin{array}{l}\text { AUS, ITA, LUX, NLD, } \\
\text { ESP, CHE }\end{array}$ & $\begin{array}{c}\text { BEL, CHL, CZE, DNK, FIN, HUN, ISL, } \\
\text { LVA, MEX, NOR, POL, PRT, SVK, } \\
\text { SVN, SWE, TUR }\end{array}$ & / \\
\hline & 2017 & $\begin{array}{l}\text { FRA, DEU, GBR, } \\
\text { USA }\end{array}$ & $\begin{array}{l}\text { ITA, JPN, LUX, NLD, } \\
\text { ESP, CHE }\end{array}$ & $\begin{array}{l}\text { AUS, BEL, CHL, CZE, DNK, FIN, HUN, } \\
\text { ISL, LVA, MEX, NOR, POL, PRT, SVK, } \\
\text { SVN, SWE, TUR }\end{array}$ & I \\
\hline
\end{tabular}


Table 5. Sensitivity analysis on changing weights of the RP criterion in 2017.

\begin{tabular}{|c|c|c|c|c|c|c|c|c|c|c|c|}
\hline & \multicolumn{10}{|c|}{ Changing Weights of the RP Criterion } \\
\hline & & \multicolumn{2}{|c|}{0.1} & \multicolumn{2}{|l|}{0.2} & \multicolumn{2}{|l|}{0.3} & \multicolumn{2}{|c|}{0.4} & \multicolumn{2}{|c|}{0.5} \\
\hline & & $\mathbf{A S}$ & Rank & $\mathbf{A S}$ & Rank & $\mathbf{A S}$ & Rank & $\mathbf{A S}$ & Rank & $\mathbf{A S}$ & Rank \\
\hline \multirow{27}{*}{ 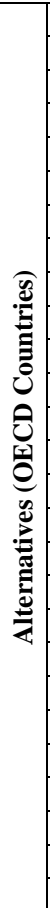 } & AUS & 0.24345 & 11 & 0.24345 & 13 & 0.21535 & 11 & 0.39336 & 13 & 0.21535 & 11 \\
\hline & BEL & 0.21315 & 13 & 0.21315 & 14 & 0.16252 & 14 & 0.38386 & 14 & 0.16252 & 14 \\
\hline & CHL & 0.041627 & 22 & 0.041627 & 19 & 0.064096 & 18 & 0.34181 & 18 & 0.06409 & 18 \\
\hline & CZE & 0.04715 & 21 & 0.047153 & 24 & 0.032276 & 23 & 0.32736 & 24 & 0.03227 & 23 \\
\hline & DNK & 0.22186 & 12 & 0.22186 & 12 & 0.20217 & 13 & 0.40999 & 10 & 0.20217 & 13 \\
\hline & FIN & $\begin{array}{l}0.095491 \\
\end{array}$ & 17 & 0.095491 & 17 & 0.06143 & 19 & 0.34763 & 17 & 0.06143 & 19 \\
\hline & FRA & 0.49923 & 3 & 0.49923 & 3 & 0.52076 & 3 & 0.50033 & 4 & 0.52076 & 3 \\
\hline & DEU & 0.49596 & 4 & 0.49596 & 4 & 0.48841 & 4 & 0.4803 & 5 & 0.48841 & 4 \\
\hline & HUN & 0.025227 & 23 & 0.025227 & 25 & 0.014423 & 26 & 0.3234 & 25 & 0.01442 & 26 \\
\hline & ISL & 0.024195 & 24 & 0.024195 & 23 & 0.022621 & 25 & 0.33194 & 23 & 0.02262 & 25 \\
\hline & ITA & 0.38187 & 6 & 0.38187 & 6 & 0.31389 & 6 & 0.42829 & 9 & 0.31389 & 6 \\
\hline & JPN & 0.46871 & 5 & 0.46871 & 5 & 0.42399 & 5 & 0.43329 & 8 & 0.42399 & 5 \\
\hline & LVA & 0.0003351 & 27 & 0.0003351 & 27 & 0 & 27 & 0.32036 & 27 & 0 & 27 \\
\hline & LUX & 0.33041 & 7 & 0.33041 & 8 & 0.30295 & 8 & 0.51665 & 3 & 0.30295 & 8 \\
\hline & MEX & 0.050334 & 20 & 0.050334 & 18 & 0.066216 & 17 & 0.33877 & 20 & 0.06621 & 17 \\
\hline & NLD & 0.24978 & 10 & 0.24978 & 7 & 0.30528 & 7 & 0.44361 & 6 & 0.30528 & 7 \\
\hline & NOR & 0.14467 & 15 & 0.14467 & 15 & 0.14192 & 15 & 0.37938 & 15 & 0.14192 & 15 \\
\hline & POL & 0.062573 & 18 & 0.062573 & 21 & 0.048711 & 21 & 0.33618 & 22 & 0.04871 & 21 \\
\hline & PRT & 0.13361 & 16 & 0.13361 & 16 & 0.085489 & 16 & 0.35393 & 16 & 0.08548 & 16 \\
\hline & SVK & 0.024097 & 25 & 0.024097 & 20 & 0.050129 & 20 & 0.34134 & 19 & 0.05012 & 20 \\
\hline & SVN & 0.055937 & 19 & 0.055937 & 22 & 0.047117 & 22 & 0.33782 & 21 & 0.04711 & 22 \\
\hline & ESP & 0.26904 & 9 & 0.26904 & 10 & 0.21983 & 10 & 0.401 & 12 & 0.21983 & 10 \\
\hline & SWE & 0.17074 & 14 & 0.17074 & 11 & 0.20536 & 12 & 0.40513 & 11 & 0.20536 & 12 \\
\hline & CHE & 0.28941 & 8 & 0.28941 & 9 & 0.27621 & 9 & 0.43333 & 7 & 0.27621 & 9 \\
\hline & TUR & 0.016805 & 26 & 0.016805 & 26 & 0.027948 & 24 & 0.32096 & 26 & 0.02794 & 24 \\
\hline & GBR & 0.52275 & 2 & 0.52275 & 2 & 0.53071 & 2 & 0.52094 & 2 & 0.53071 & 2 \\
\hline & USA & 0.98744 & 1 & 0.98744 & 1 & 1 & 1 & 0.53 & 1 & 1 & 1 \\
\hline
\end{tabular}


Table 5. Sensitivity analysis on changing weights of the RP criterion in 2017. (continued)

\begin{tabular}{|c|c|c|c|c|c|c|c|c|c|}
\hline & \multicolumn{8}{|c|}{ Changing Weights of the RP Criterion } \\
\hline & & \multicolumn{2}{|c|}{0.6} & \multicolumn{2}{|c|}{0.7} & \multicolumn{2}{|c|}{0.8} & \multicolumn{2}{|c|}{0.9} \\
\hline & & AS & Rank & AS & Rank & AS & Rank & AS & Rank \\
\hline \multirow{27}{*}{ 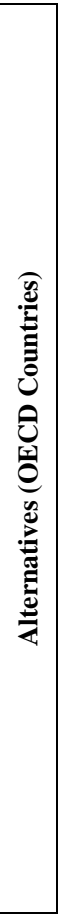 } & AUS & 0.32823 & 14 & 0.20236 & 13 & 0.39191 & 11 & 0.34823 & 12 \\
\hline & BEL & 0.34574 & 12 & 0.15949 & 14 & 0.37152 & 15 & 0.34574 & 13 \\
\hline & CHL & 0.31605 & 17 & 0.05552 & 19 & 0.33658 & 21 & 0.31605 & 19 \\
\hline & CZE & 0.29938 & 23 & 0.01966 & 24 & 0.33189 & 24 & 0.2993 & 23 \\
\hline & DNK & 0.33258 & 13 & 0.20792 & 12 & 0.37184 & 14 & 0.33258 & 14 \\
\hline & FIN & 0.30918 & 20 & 0.06606 & 17 & 0.34725 & 17 & 0.31918 & 18 \\
\hline & FRA & 0.5211 & 2 & 0.52054 & 3 & 0.44981 & 4 & 0.5211 & 4 \\
\hline & DEU & 0.51632 & 4 & 0.48701 & 4 & 0.49414 & 2 & 0.61632 & 3 \\
\hline & HUN & 0.29689 & 25 & 0.00922 & 25 & 0.3301 & 25 & 0.29689 & 25 \\
\hline & ISL & 0.28952 & 27 & 0.02598 & 23 & 0.33951 & 20 & 0.28952 & 27 \\
\hline & ITA & 0.42824 & 6 & 0.31967 & 6 & 0.41426 & 6 & 0.42824 & 6 \\
\hline & JPN & 0.48396 & 5 & 0.4249 & 5 & 0.41528 & 5 & 0.48396 & 5 \\
\hline & LVA & 0.2924 & 26 & 0.00034 & 27 & 0.32699 & 26 & 0.2924 & 26 \\
\hline & LUX & 0.36572 & 9 & 0.29868 & 8 & 0.39757 & 10 & 0.39872 & 8 \\
\hline & MEX & 0.30159 & 22 & 0.05577 & 18 & 0.35054 & 16 & 0.32159 & 17 \\
\hline & NLD & 0.40178 & 7 & 0.31286 & 7 & 0.4078 & 8 & 0.40178 & 7 \\
\hline & NOR & 0.32431 & 15 & 0.14344 & 15 & 0.37643 & 13 & 0.32431 & 15 \\
\hline & POL & 0.31376 & 18 & 0.04473 & 21 & 0.34105 & 19 & 0.31376 & 20 \\
\hline & PRT & 0.32407 & 16 & 0.08276 & 16 & 0.34366 & 18 & 0.32407 & 16 \\
\hline & SVK & 0.31081 & 19 & 0.04994 & 20 & 0.33337 & 22 & 0.31081 & 21 \\
\hline & SVN & 0.30435 & 21 & 0.04124 & 22 & 0.33201 & 23 & 0.30435 & 22 \\
\hline & ESP & 0.3892 & 8 & 0.2201 & 10 & 0.39845 & 9 & 0.3892 & 9 \\
\hline & SWE & 0.35436 & 11 & 0.21118 & 11 & 0.39118 & 12 & 0.35436 & 11 \\
\hline & CHE & 0.3604 & 10 & 0.2788 & 9 & 0.41161 & 7 & 0.3604 & 10 \\
\hline & TUR & 0.29885 & 24 & 0.00868 & 26 & 0.32489 & 27 & 0.29885 & 24 \\
\hline & GBR & 0.51911 & 3 & 0.53053 & 2 & 0.49272 & 3 & 0.61911 & 2 \\
\hline & USA & 0.96629 & 1 & 0.98496 & 1 & 0.5 & 1 & 0.96629 & 1 \\
\hline
\end{tabular}

